\title{
Short communication: Sensitive detection of norbixin in dried dairy ingredients at concentrations of less than 1 part per billion
}

\author{
B. G. Carter, C. W. Park, and M. A. Drake ${ }^{1}$ \\ Department of Food, Bioprocessing and Nutrition Sciences, Southeast Dairy Foods Research Center, North Carolina State University, \\ Raleigh 27695
}

\begin{abstract}
Norbixin is the water-soluble carotenoid in annatto extracts used in the cheese industry to color Cheddar cheese. The purpose of norbixin is to provide cheese color, but norbixin is also present in the whey stream and contaminates dried dairy ingredients. Regulatory restrictions dictate that norbixin cannot be present in dairy ingredients destined for infant formula or ingredients entering different international markets. Thus, there is a need for the detection and quantification of norbixin at very low levels in dried dairy ingredients to confirm its absence. A rapid method for norbixin evaluation exists, but it does not have the sensitivity required to confirm norbixin absence at very low levels in compliance with existing regulations. The current method has a limit of detection of $2.7 \mu \mathrm{g} / \mathrm{kg}$ and a limit of quantification of $3.5 \mu \mathrm{g} / \mathrm{kg}$. The purpose of this study was to develop a method to extract and concentrate norbixin for quantification in dried dairy ingredients below $1 \mu \mathrm{g} / \mathrm{kg}$ (1 ppb). A reverse-phase solid-phase extraction column step was applied in the new method to concentrate and quantify norbixin from liquid and dried WPC80 (whey protein concentrate with $80 \%$ protein), WPC34 (WPC, $34 \%$ protein), permeate, and lactose. Samples were evaluated by both methods for comparison. The established method was able to quantify norbixin in whey proteins and permeates $(9.39 \mu \mathrm{g} / \mathrm{kg}$ to $2.35 \mathrm{mg} / \mathrm{kg})$ but was unable to detect norbixin in suspect powdered lactose samples. The newly developed method had similar performance to the established method for whey proteins and permeates but was also able to detect norbixin in powdered lactose samples. The proposed method had a >90\% recovery in lactose samples and a limit of detection of $28 \mathrm{ppt}(\mathrm{ng} / \mathrm{kg})$ and a limit of quantification of 94
\end{abstract}

Received April 29, 2017.

Accepted July 9, 2017.

${ }^{1}$ Corresponding author: maryanne_drake@ncsu.edu ppt $(\mathrm{ng} / \mathrm{kg})$. The developed method provides detection and quantification of norbixin for dairy ingredients that have a concentration of $<1 \mathrm{ppb}$.

Key words: norbixin, annatto, whey, high performance liquid chromatography

\section{Short Communication}

Cheddar cheese, one of the most commonly produced cheeses in the United States, makes up $31.7 \%$ of the 5.05 million tonnes of cheese produced in 2009 (USDA, 2010). The colorant used to give Cheddar cheese its iconic orange color is annatto (Kang et al., 2010). The main carotenoid in annatto extract is norbixin. Approximately $10 \%$ of norbixin added to the cheese milk is present in fluid whey produced from Cheddar cheese manufacture, and steps such as bleaching with hydrogen peroxide or benzoyl peroxide are required to remove the colorant from the whey stream (Smith et al., 2014). Even after the most effective bleaching treatments, including enzymatic treatments, norbixin can still be detected (Campbell et al., 2012; Campbell and Drake, 2014; Smith et al., 2014). The goal of bleaching is not to destroy norbixin but simply to reduce the overall orange color in the whey stream. Regulatory restrictions limit the carryover of norbixin from colored cheeses into dried whey ingredients destined for infant formula as well as ingredients entering international commerce. Thus, analytical methods are required to confirm the absence of norbixin (EC, 1989, 2008).

An easy, quick, and affordable method for norbixin extraction and measurement exists (Campbell et al., 2014). Previous methods were laborious and expensive and relied on spectrophotometric and colorimetric methods (Scotter et al., 1998; Croissant et al., 2009). This method was designed to be rapid, lower costs, and limit the amount of solvent needed. The method of Campbell et al. (2014) is sufficient to measure norbixin in cheese milk, fluid whey, and dried ingredients with low concentrations of norbixin $(9.39 \mu \mathrm{g} / \mathrm{L}$ to 2.35 $\mathrm{mg} / \mathrm{L}$ ) but is not sensitive enough to measure very low concentrations (30 ng/L to $1 \mu \mathrm{g} / \mathrm{L}$ ) of norbixin in dried 
dairy ingredients to confirm compliance of existing regulations. Multiple whey streams may be commingled before further processing, diluting norbixin levels, and these low concentrations may not be detected by current methods. Therefore, the objective of the current study was to develop a method with a lower limit of detection (LOD) to measure norbixin levels below 1 $\mathrm{ug} / \mathrm{mg}$. Application of the new method ranges from measuring the efficacy of bleaching treatments in whey protein concentrate (WPC) and whey protein isolate from colored cheese to detecting low norbixin concentrations in permeate and lactose or whey products that have been commingled.

Commercial samples of lactose $(\mathrm{n}=20)$, whey protein $(\mathrm{n}=5)$, and permeates $(\mathrm{n}=3)$ were analyzed by a previous method (Campbell and Drake, 2014) to measure norbixin as well as by the new proposed method for direct comparison in duplicate. The new proposed method uses a solid-phase extraction (SPE) column to capture the norbixin from a dilute solution and concentrates it for easy quantification. This process increases the sample preparation time, but time is sacrificed for sensitive norbixin detection. Sample preparations were conducted under lights with UV light filters to avoid degradation by UV light.

Five grams of lactose was mixed with $5 \mathrm{~mL}$ of deionized water and allowed to hydrate. Then $5 \mathrm{~mL}$ of acetonitrile (Fisher Scientific, Waltham, MA) was added and samples were vortexed and centrifuged at 10,000 $\times g$ for $5 \mathrm{~min}$. The supernatant was removed from the pellet into another tube, and $10 \mathrm{~mL}$ of water was added to the sample, vortexed to dissolve the pellet, and centrifuged again. A reverse-phase Discovery DSC-18 500-mg, 6-mL SPE column (Sigma-Aldrich, St. Louis, MO) with 500 $\mathrm{mg}$ of sorbent material was conditioned with $3 \mathrm{~mL}$ of methanol (Fisher Scientific) and equilibrated with $6 \mathrm{~mL}$ of water. The sample was then loaded onto the column at a rate of $1 \mathrm{~mL} / \mathrm{min}$. Norbixin was eluted with $3 \mathrm{~mL}$ of 98:2 solution of methanol and formic acid (Sigma Aldrich). The sample was then evaporated to dryness, rehydrated in $200 \mu \mathrm{L}$ of mobile phase, transferred to an Eppendorf tube, and centrifuged at 14,000 $\times g$ for $5 \mathrm{~min}$. The supernatant was removed and placed into an HPLC vial with a glass insert (MicroLiter Analytical Supplies, Suwanee, GA) for injection. These same samples were also subjected to the previous established method described by Campbell et al. (2014) for direct comparison.

Commercial and pilot plant-manufactured liquid sweet whey $(\mathrm{n}=2)$ and powdered WPC 34 (WPC with $34 \%$ protein; $\mathrm{n}=2$ ), WPC 80 (WPC with $80 \%$ protein; $\mathrm{n}=2$ ), and whey protein isolate $(2)$ were sourced to evaluate the new norbixin extraction procedure. One gram of powder was rehydrated in $5 \mathrm{~mL}$ of deionized water and allowed to mix for $1 \mathrm{~h}$. Five milliliters of acetonitrile was added to a total volume of $10 \mathrm{~mL}$. The samples were then centrifuged at $10,000 \times g$ for 5 min. The supernatant was removed from the pellet into another tube, and $10 \mathrm{~mL}$ of water was added to the sample, vortexed to dissolve the pellet, and centrifuged again. To extract liquid samples, $5 \mathrm{~mL}$ of liquid was combined with $5 \mathrm{~mL}$ of acetonitrile and then processed through the 2 stages of centrifugation as stated previously. Both liquid and powder samples were treated as lactose samples with the SPE step and evaporation.

Commercial liquid and powder whey permeates $(\mathrm{n}=$ 3) were also evaluated by the established and the new proposed methods. The powders were rehydrated in deionized water as previously described. Liquid samples were adjusted to $10 \%$ solids and treated as the samples above. Samples were prepared as described above with 2 centrifugation steps, SPE, and evaporation.

The liquid chromatography system was an Acquity UPLC (Waters, Milford, MA). For chromatographic analysis, $10 \mu \mathrm{L}$ of sample was injected onto a Waters BEH C18 column $(1.7 \mu \mathrm{m}$ particle size, $50 \mathrm{~mm} \times 2.1$ $\mathrm{mm})$. Isocratic conditions were used with the mobile phase consisting of $70 \%$ acetonitrile and $30 \%$ water with $0.1 \%$ formic acid. A photodiode array detector was used, and detection was performed with a wavelength of $459 \mathrm{~nm}$.

In this study, LOD and limit of quantification (LOQ) were determined based on the norbixin concentration level that generated a signal:noise ratio of $1: 3$ and $1: 10$. Uncolored powdered lactose samples ( $5 \%$ solids wt/vol) were prepared with decreasing concentrations of norbixin and were injected to find where the signal was 3 times greater than the noise intensity and find a signal: noise ratio of $1: 3$ and 1:10. The samples were injected 3 times, and the relative standard deviation between injections was below $10 \%$.

To determine that the relationship of norbixin concentration and signal from the instrument was linear, norbixin was quantified in lactose solutions $(5 \%$ solids wt/vol) over a wide range $(0-300 \mathrm{ng} / \mathrm{mL})$ of concentrations. The concentrations were made by making a stock solution of known concentration of norbixin and then making dilutions over the previously stated range. The concentration was graphed in comparison with peak area, and linearity was calculated using linear regression.

To measure the efficacy of norbixin extraction in the new proposed method, 3 different known concentrations of norbixin were added to lactose solutions (5\% 
Table 1. Norbixin detection and concentration from powdered lactose samples $(\mathrm{n}=20)$

\begin{tabular}{lcc}
\hline Sample ID & $\begin{array}{c}\text { Norbixin } \\
\text { concentration with } \\
\text { previous method }\end{array}$ & $\begin{array}{c}\text { Norbixin } \\
\text { concentration with } \\
\text { new method }(\mu \mathrm{g} / \mathrm{kg})\end{array}$ \\
\hline Lactose 1 & $\mathrm{ND}^{1}$ & 0.116 \\
Lactose 2 & $\mathrm{ND}$ & 0.950 \\
Lactose 3 & $\mathrm{ND}$ & 0.304 \\
Lactose 4 & $\mathrm{ND}$ & $<0.056$ \\
Lactose 5 & $\mathrm{ND}$ & $\mathrm{ND}$ \\
Lactose 6 & $\mathrm{ND}$ & $\mathrm{ND}$ \\
Lactose 7 & $\mathrm{ND}$ & $\mathrm{ND}$ \\
Lactose 8 & $\mathrm{ND}$ & $\mathrm{ND}$ \\
Lactose 9 & $\mathrm{ND}$ & $\mathrm{ND}$ \\
Lactose 10 & $\mathrm{ND}$ & $\mathrm{ND}$ \\
Lactose 11 & $\mathrm{ND}$ & $\mathrm{ND}$ \\
Lactose 12 & $\mathrm{ND}$ & 0.232 \\
Lactose 13 & $\mathrm{ND}$ & $\mathrm{ND}$ \\
Lactose 14 & $\mathrm{ND}$ & $\mathrm{ND}$ \\
Lactose 15 & $\mathrm{ND}$ & 0.168 \\
Lactose 16 & $\mathrm{ND}$ & $\mathrm{ND}$ \\
Lactose 17 & $\mathrm{ND}$ & $<0.056$ \\
Lactose 18 & $\mathrm{ND}$ & $\mathrm{ND}$ \\
Lactose 19 & $\mathrm{ND}$ & $\mathrm{ND}$ \\
Lactose 20 & $\mathrm{ND}$ & \\
\hline
\end{tabular}

${ }^{1} \mathrm{ND}=$ not detected

solids wt/vol) from uncolored cheese. The samples were then subjected to the new extraction method and quantified. The quantity of norbixin was determined by comparison with the initial concentration based on weight to establish an extraction efficiency percentage. The samples were tested in duplicate.

The previous and proposed methods were compared in terms of extraction time as well as the cost of analysis. Data were analyzed by ANOVA between the liquid and powder of each protein category (XLSTAT, version 2013.5.03; Addinsoft, New York, NY). Differences were analyzed by Tukey's honestly significant difference test.

Norbixin was detected in 7 out of 20 powdered lactose samples that were tested with the new proposed method versus 0 that were tested with the previous method (Table $1 ; P<0.05$ ). The new method allows for quantification of norbixin at very low levels in highly processed dairy ingredients such as lactose powder. Figure 1 shows an example of chromatograms of the 2 methods for comparison.
In fluid whey and whey protein ingredients, norbixin was detected by both methods in the range of $15.2 \mu \mathrm{g} /$ $\mathrm{kg}$ to $2.35 \mathrm{mg} / \mathrm{kg}(P>0.05$; results not shown). This result was expected because norbixin is concentrated with protein during filtration due to association with the milk fat globule membrane, which is also retained by the ultrafiltration membranes (Zhu and Damodaran, 2012). The new proposed method is not designed to replace the previous method for measurement of norbixin in samples with moderate levels of norbixin but rather allows quantification when positive samples may go undetected by other methods. The benefit of the previous method (Campbell et al., 2014) is that it is inexpensive and quick and uses minimal solvent.

Permeate norbixin levels were also detected by both methods in the range of $30.2 \mu \mathrm{g} / \mathrm{kg}$ to $4.5 \mathrm{mg} / \mathrm{kg}(P$ $>0.05$; results not shown). The LOD and LOQ of the previous method in fluid whey were 2.7 and $3.5 \mu \mathrm{g} /$ $\mathrm{kg}$, respectively (Campbell et al., 2014). With the new method, the LOD and LOQ were decreased to an LOD of $28 \mathrm{ppt}(\mathrm{ng} / \mathrm{kg})$ and an LOQ of $94 \mathrm{ppt}(\mathrm{ng} / \mathrm{kg})$. The LOD and LOQ determinations were generated from spiked lactose solutions from uncolored whey to account for background interference to be calculated into these limits.

Norbixin detection was linear in lactose solutions $(0-$ $1,000 \mathrm{ng} / \mathrm{mL}$ ). Linearity was determined using linear regression, and $R^{2}$ values were $>0.99$, indicating that norbixin can be extracted over a range of low values.

Three different levels of norbixin were spiked into lactose solutions. Calculations of initial concentrations based on weight of standard were compared with quantified norbixin concentrations measured by ultra-performance liquid chromatography to determine extraction efficiency. All tested samples subjected to the new extraction procedure had $>90 \%$ recovery. Previous studies have reported similar values for recovery of norbixin from foods. Noppe et al. (2009) reported a recovery of between 99 and 102\% for extractions of norbixin from meat tissues. In cheese, yogurt, and butter, recovery rates of 75 to $96 \%$ have been reported (Scotter et al., 2002). Campbell et al. (2014) also reported $>90 \%$ recovery. The proposed method has a lower LOD and LOQ without sacrificing norbixin recovery.

Table 2. Cost and time analysis of the 2 methods

\begin{tabular}{lll}
\hline Item & Campbell et al. (2014) & Proposed method \\
\hline Total waste & $24 \mathrm{~mL}$ (acetonitrile, water) & $11 \mathrm{~mL}$ (acetonitrile, methanol, water) \\
Total extraction time & $15 \mathrm{~min}$ & $1.5 \mathrm{~h}$ \\
Total cost & $\$ 3.21$ & $\$ 4.61$ \\
Limit of detection & $2.7 \mathrm{ppb}(\mu \mathrm{g} / \mathrm{kg})$ & $28 \mathrm{ppt}(\mathrm{ng} / \mathrm{kg})$ \\
Limit of quantification & $3.5 \mathrm{ppb}(\mu \mathrm{g} / \mathrm{kg})$ & $57 \mathrm{ppt}(\mathrm{ng} / \mathrm{kg})$ \\
\hline
\end{tabular}



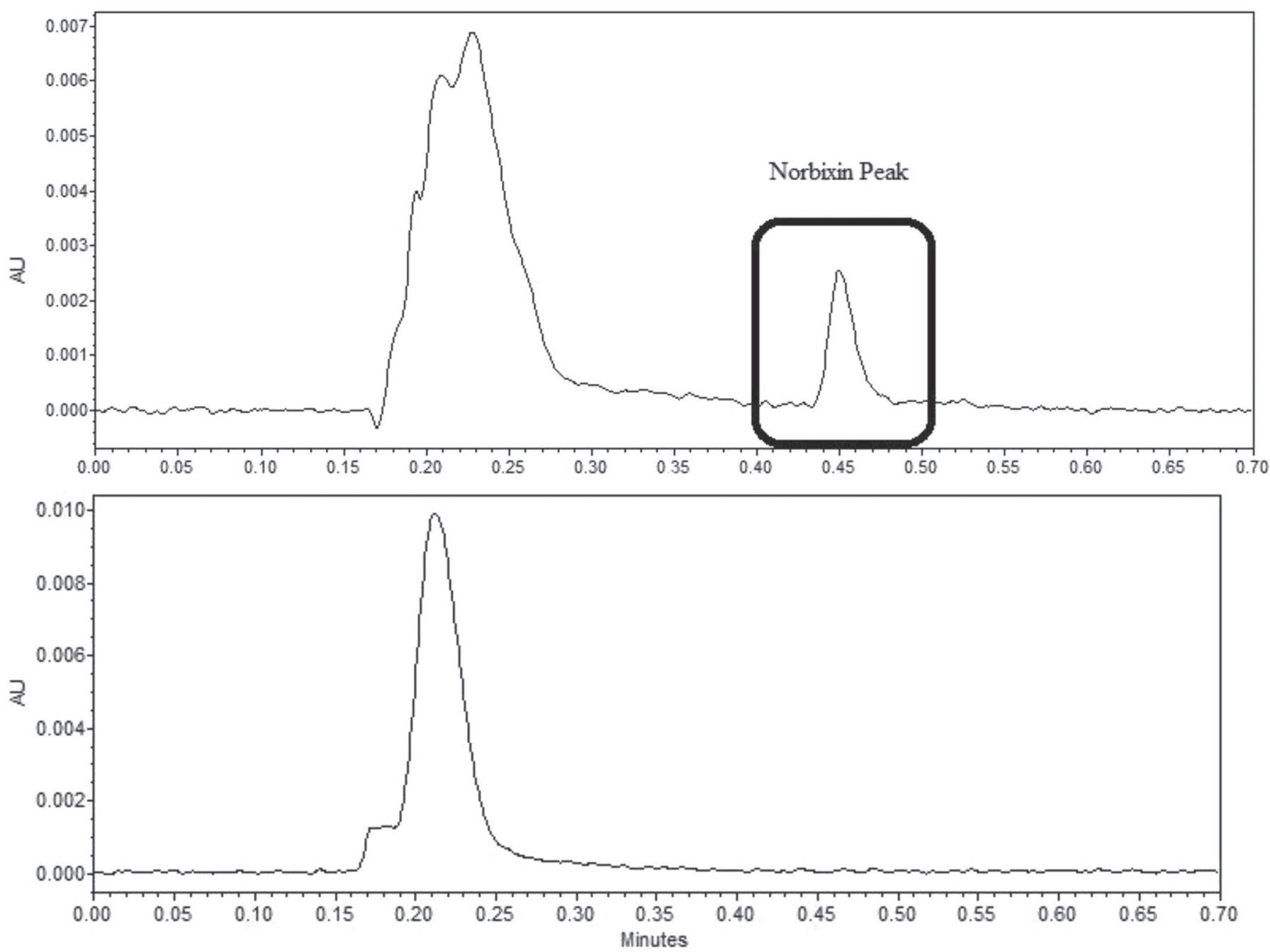

Figure 1. Norbixin extracted from lactose by the new method (top) and the previous method (bottom) at $459 \mathrm{~nm}$.

Table 2 contrasts the cost and time of the 2 compared analyses. The costs of the new method are slightly higher with the addition of the SPE column.

The developed method provides a highly sensitive norbixin extraction procedure for dried dairy ingredients. The developed method is not as quick as the previous method, but time is sacrificed for increased sensitivity. The new proposed method is novel in its ability to measure norbixin at very low concentrations $(<1 \mu \mathrm{g} / \mathrm{kg})$.

\section{ACKNOWLEDGMENTS}

Funding was provided in part by the National Dairy Council (Rosemont, IL). The use of trade names does not imply endorsement nor lack of endorsement of those not mentioned.

\section{REFERENCES}

Campbell, R. E., I. A. L. A. Boogers, and M. A. Drake. 2014. Development of a novel method for the extraction of norbixin from whey and its subsequent quantification via high performance liquid chromatography. J. Dairy Sci. 97:1313-1318.

Campbell, R. E., and M. A. Drake. 2014. Enzymatic bleaching in commercial colored Cheddar whey retentates. Int. Dairy J. 38:148-153.

Campbell, R. E., E. J. Kang, E. Bastian, and M. A. Drake. 2012. The use of lactoperoxidase for the bleaching of fluid whey. J. Dairy Sci. 95:2882-2890.

Croissant, A. E., E. J. Kang, R. E. Campbell, E. Bastian, and M. A. Drake. 2009. The effect of bleaching agent on the flavor of liquid whey and whey protein concentrate. J. Dairy Sci. 92:5917-5927.

EC (European Community). 1989. Council Directive 89/398/EEC of 3 May 1989 on the approximation of the laws of the member states relating to foodstuffs intended for particular nutritional uses. Off. J. Eur. Union L 186:27-32.

EC (European Community). 2008. Regulation (EC) no. 1333/2008 of the European Parliament and of the Council of 16 December 2008 on food additives. Off. J. Eur. Union L 354:16-33.

Kang, E. J., R. E. Campbell, E. Bastian, and M. A. Drake. 2010. Annatto and bleaching in dairy foods. J. Dairy Sci. 93:3891-3901. 
Noppe, H., A. Mertinez, K. Verheyden, J. Van Loco, R. Companyo Beltran, and H. F. de Brabander. 2009. Determination of bixin and norbixin in meat using liquid chromatography and photodiode array detection. Food Addit. Contam. Part A Chem. Anal. Control Expo. Risk Assess. 26:17-24.

Scotter, M. J., L. Castle, C. A. Honeybone, and C. Nelson. 2002 Method development and analysis of retail foods for annatto food colouring material. Food Addit. Contam. 19:205-222.

Scotter, M. J., L. A. Wilson, G. P. Appleton, and L. Castle. 1998 Analysis of annatto food coloring formulations. Determination of coloring components and colored thermal degradation products by high-performance liquid chromatography with photodiode array detection. J. Agric. Food Chem. 46:1031-1038.

Smith, T. J., X. E. Li, and M. A. Drake. 2014. Norbixin and bixin partitioning in Cheddar cheese and whey. J. Dairy Sci. 97:3321-3327.

USDA. 2010. Agricultural Statistics 2010. National Agricultural Statistics Service. Accessed Aug. 6, 2015. https://www.nass.usda.gov/ Publications/Ag_Statistics/2010/2010.pdf.

Zhu, D., and S. Damodaran. 2012. Annatto in Cheddar cheese-derived whey protein concentrate is primarily associated with milk fat globule membrane. J. Dairy Sci. 95:614-617. 